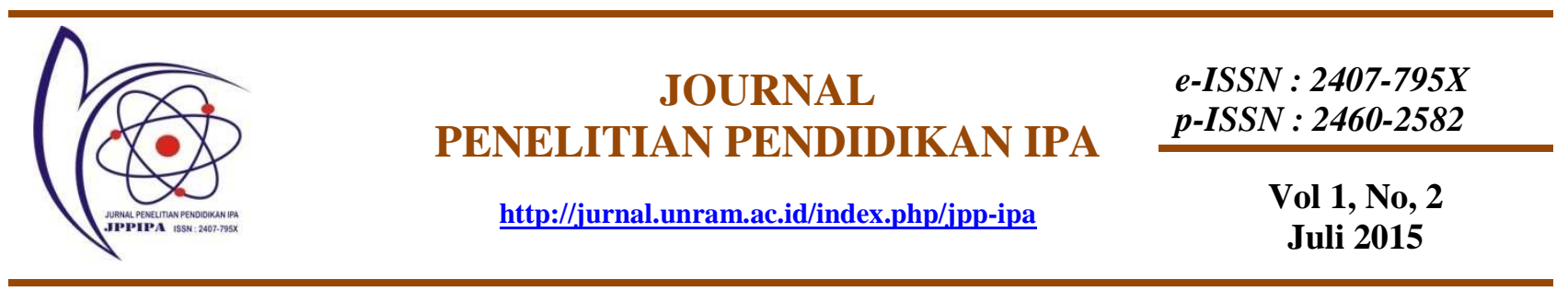

\title{
PENGEMBANGAN PERANGKAT MODEL PEMBELAJARAN KUANTUM BERBASIS MASALAH DENGAN PENDEKATAN SAINTIFIK
}

\author{
Mei Indra Jayanti' ${ }^{1,}$ A. Wahab Jufri ${ }^{2}$, Agus Ramdani \\ Program Studi Magister Pendidikan IPA Program Pascasarjana Universitas Mataram ${ }^{123}$ \\ meiindraj@yahoo.co.id
}

\begin{tabular}{l}
\hline Key Words \\
\hline PKBM, \\
PKTBM, \\
scientific \\
approach, \\
critical thinking \\
ability, \\
reasoning \\
ability
\end{tabular}

\begin{tabular}{|c|c|}
\hline Kata Kunci & Abstrak \\
\hline $\begin{array}{l}\text { Perangkat } \\
\text { model PKBM, } \\
\text { Perangkat } \\
\text { model PKTBM, } \\
\text { Pendekatan } \\
\text { saintifik, } \\
\text { Kemampuan } \\
\text { berpikir kritis, } \\
\text { kemampuan } \\
\text { berargumen }\end{array}$ & $\begin{array}{l}\text { Dalam Undang-Undang Republik Indonesia Nomor } 20 \text { Tahun } 2003 \text { tentang sistem } \\
\text { pendidikan nasional pasal } 1 \text { ayat } 1 \text { dinyatakan bahwa pendidikan dikatakan berhasil } \\
\text { dalam kegiatan pembelajaran apabila siswa dapat mencapai kompetensi yang } \\
\text { diharapkan dari ilmu pengetahuan dan memberikan nilai positif bagi dirinya. } \\
\text { Kemampuan berpikir kritis dan kemampuan berargumen merupakan bagian dari } \\
\text { tujuan mata pelajaran biologi di SMA yang dapat dikembangkan melalui } \\
\text { pembelajaran yang berpusat pada siswa, seperti pembelajaran kuantum, } \\
\text { pembelajaran berbasis masalah, dan pendekatan saintifik. Penelitian ini bertujuan } \\
\text { untuk mengembangkan perangkat model pembelajaran kuantum berbasis masalah dan } \\
\text { perangkat model pembelajaran kuantum tanpa berbasis masalah ( PKBM dan } \\
\text { PKTBM) dengan pendekatan saintifik } 4 \text { dan } 6 \text { tahap terhadap kemampuan berpikir } \\
\text { kritis dan kemampuan berargumen pada siswa kelas X. Proses pengembangan } \\
\text { perangkat pembelajaran mengacu pada model Dick \& Carey. Perangkat } \\
\text { pembelajaran dikembangkan untuk mata pelajaran biologi kelas X SMA pada materi } \\
\text { ekologi. Data dikumpulkan menggunakan instrumen karakteristik kelayakan } \\
\text { perangkat pembelajaran. Data dianalisis dengan menggunakan statistik deskriptif. } \\
\text { Hasil penelitian menunjukkan bahwa perangkat pembelajaran berupa silabus dan } \\
\text { RPP mendapat kategori layak; lembar kerja siswa, tes kemampuan berpikir kritis dan } \\
\text { tes kemampuan berargumen mendapat kategori sangat layak untuk diterapkan siswa } \\
\text { kelas X }\end{array}$ \\
\hline
\end{tabular}

In the Law of the Republic of Indonesia Number 20 of 2003 on the national education system of article 1, paragraph 1 that education will be successful in learning activities where students are able to achieve the expected competencies of science and give a positive value to themselves. Critical thinking ability and reasoning ability is part of the high school biology course goals that can be developed through a student-centered learning, such as quantum learning, problem-based learning, and scientific approach. This study aimed to develop the quantum problem-based learning model packages and the quantum without problem-based learning (PKBM and PKTBM) with 4 and 6 stage of scientific approach toward critical thinking ability and reasoning ability in tenth grades. Process of development teaching and learning packages refers to the model Dick \& Carey. Teaching and learning packages developed to biology course for the tenth grade of senior high school in ecological material. Data were collected by using instruments feasibility characteristics of teaching and learning packages. Data were analyzed using descriptive statistics. The results showed that the syllabus and the learning lesson plan (RPP) got a worthy category; worksheets, tests of critical thinking ability and tests of reasoning ability got a very worthy category to used in tenth grades of senior high school.

Kata Kunci model PKBM, Perangkat model PKTBM, Pendekatan saintifik, Kemampuan berpikir kritis, kemampuan 


\section{PENDAHULUAN}

Berdasarkan Undang-Undang Republik Indonesia Nomor 20 tahun 2003 tentang sistem pendidikan nasional pasal 1 ayat 1 dinyatakan bahwa pendidikan adalah usaha sadar dan terencana untuk mewujudkan suasana belajar dan proses pembelajaran agar peserta didik secara aktif mengembangkan potensi dirinya untuk memiliki kekuatan spiritual keagamaan, pengendalian diri, kepribadian, kecerdasan, akhlak mulia, serta keterampilan yang diperlukan dirinya, masyarakat, bangsa, dan negara. Berdasarkan hal tersebut dapat dirinci bahwa proses pendidikan dalam kegiatan pembelajaran dikatakan berhasil apabila siswa mampu mencapai kompetensi ilmu yang diharapkan dan memberikan nilai yang positif terhadap dirinya.

Berdasarkan data hasil tes PISA tahun 2012 diketahui bahwa siswa Indonesia usia 15 tahun tidak mampu menjawab soal-soal tes pada level 5 dan 6 yang merupakan soal-soal kompleks sehingga membutuhkan kemampuan berpikir tingkat tinggi yang melibatkan aktifitas kognitif berupa kemampuan berpikir kritis dan kemampuan berargumen (OECD, 2013). Krulik dan Rudnick (1996, dalam Arnyana, 2006) mengemukakan bahwa berpikir kritis adalah kemampuan untuk memecahkan masalah yang dihadapi oleh seseorang. Agar mampu memecahkan masalah dengan baik dituntut kemampuan analisis, sintesis, evaluasi, generalisasi, membandingkan, mendeduksi, mengklasifikasi informasi, menyimpulkan, dan mengambil keputusan. Menurut Erdurane, et al., (2004) bahwa pembelajaran sains dianggap melibatkan konstruksi dan penggunaan alat-alat yang berperan penting dalam pengetahuan tentang alam. Dalam hal ini, kerangka argumentasi adalah alat yang berperan signifikan dalam pertumbuhan pengetahuan ilmiah serta komponen penting dari wacana ilmiah.

Kemampuan berpikir kritis dan kemampuan berargumen membutuhkan pembiasaan dalam proses pembelajaran agar siswa dapat mencapai kompetensi keilmuan dan menyelesaikan masalah yang ditemukan dalam kehidupan nyata. Salah satu cara yang dapat ditempuh oleh guru selaku fasilitator dalam kegiatan pembelajaran adalah dengan menerapkan pola pembelajan student centered. Model-model pembelajaran yang menekankan pada pola student centered antara lain yaitu model pembelajaran kuantum, pembelajaran berbasis masalah (PBM), dan pendekatan saintifik. Tahap-tahap dalam pembelajaran kuantum pada pokok bahasan ekosistem menuntut siswa untuk lebih aktif membaca, memahami, mendiskusikan masalah, mengembangkan pengetahuan yang didapat, melakukan percobaan serta mempresentasikan pengetahuan yang telah mereka 
peroleh di depan kelas, sehingga pembelajaran menjadi lebih interaktif (Prasetyo, dkk, 2012).

Belajar berdasarkan masalah adalah startegi pembelajaran yang dasar filosofinya konstruktivisme. Landasan falsafah pendekatan kontekstual adalah konstruktivisme, yaitu falsafah pembelajaran yang memberi penekanan bahwa siswa belajar tidak hanya sekadar menghafal (Suryawati, 2012). Proses inilah yang mendukung siswa menjadi pebelajar aktif dengan mengkonstruksi informasi yang diperolehnya selama kegiatan pembelajaran.

Pendekatan saintifik dimaksudkan untuk memberikan pemahaman kepada peserta didik dalam mengenal, memahami berbagai materi menggunakan pendekatan ilmiah, bahwa informasi bisa berasal dari mana saja, kapan saja, tidak tergantung pada informasi satu arah dari guru (Dokomen Bahan Ajar ToT Implementasi Kurikulum 2013, 2013).

\section{METODE PENELITIAN}

Penelitian ini merupakan penelitian pengembangan yang mengacu pada model Dick \& Carey (2001). Tahap-tahapan dalam pengembangan perangkat pembelajaran meliputi : (1) Identifikasi tujuan pengajaran, (2) Analisis instruksional, (3) Analisis siswa dan konteks, (4) Penetapan tujuan pembelajaran, (5) Pengembangan instrumen penilaian hasil belajar, (6) pengembangan strategi pembelajaran, (7) pengembangan dan pemilihan materi pembelajaran, (8) evaluasi formatif, (9) revisi perangkat.

Tahap evaluasi formatif dilakukan dalam 2 (dua) tahapan. Tahap pertama yaitu validasi perangkat dan tahap kedua yaitu uji kelompok kecil. Data penelitian dikumpulkan menggunakan instrumen pengumpulan data kelayakan perangkat pembelajaran. Instrumen tersebut diberikan kepada 3 (tiga) validator dan kelompok uji coba yang berjumlah 10 orang siswa (5 siswa dan 5 siswi). Perangkat pembelajaran divalidasi oleh para ahli dan dinilai oleh kelompok uji coba sehingga diperoleh skor kelayakan perangkat pembelajaran.

Skor kelayakan perangkat pembelajaran $(\mathrm{N})$ dihitung menggunakan rumus berikut (Sugiyono, 2009) :

$$
N=\sum \frac{\text { skor perolehan }}{\text { skor ideal }}
$$

Selanjutnya ditentukan rentang nilai (RN) untuk menentukan kriteria perangkat dengan rumus sebagai berikut (Sugiyono, 2009) :

$$
R N=\frac{\sum \text { skor ideal }- \text { skor ideal }}{\sum \text { indikator }}
$$


Setelah data dikumpulkan dan dianalisis maka dapat ditentukan kriteria kelayakan perangkat pembelajaran sesuai Tabel 1 .

Tabel 1. Kriteria kelayakan perangkat pembelajaran pada uji ahli

\begin{tabular}{clll}
\hline No. & $\begin{array}{c}\text { Komponen } \\
\text { perangkat }\end{array}$ & Rentang Nilai & \multicolumn{1}{c}{ Kriteria } \\
\hline 1 & Silabus & $36,40-40,00$ & Sangat Layak \\
& & $32,70-36,39$ & Layak \\
& & $29,00-32,69$ & Kurang Layak \\
& & $\leq 28,90$ & Tidak Layak \\
2. & RPP & $40,36-44,00$ & Sangat Layak \\
& & $36,71-40,35$ & Layak \\
& & $33,06-36,70$ & Kurang Layak \\
& & $\leq 33,05$ & Tidak Layak \\
3. & LAS & $32,45-36,00$ & Sangat Layak \\
& & $28,89-32,44$ & Layak \\
& & $25,33-28,88$ & Kurang Layak \\
& & $\leq 25,32$ & Tidak Layak \\
4. & Tes kemampuan & $28,50-32,00$ & Sangat Layak \\
& berpikir kritis dan & $24,99-28,49$ & Layak \\
& tes kemampuan & $21,48-24,98$ & Kurang Layak \\
& berargumen & $\leq 21,47$ & Tidak Layak \\
\hline
\end{tabular}

Tabel 2. Kriteria kelayakan perangkat pembelajaran pada uji kelompok kecil

\begin{tabular}{cll}
\hline Komponen perangkat & \multicolumn{1}{c}{ Rentang Nilai } & \multicolumn{1}{c}{ Kriteria } \\
\hline LAS & $16,8-20,0$ & Sangat Layak \\
& $13,5-16,7$ & Layak \\
& $10,5-13,4$ & Kurang Layak \\
& $\leq 10,4$ & Tidak Layak \\
\hline
\end{tabular}

\section{HASIL DAN PEMBAHASAN}

Perangkat pembelajaran yang dikembangkan meliputi silabus, RPP, LAS (Lembar Aktifitas Siswa), tes kemampuan berpikir kritis, dan tes kemampuan berargumen. Terdapat 4 (empat) jenis silabus dan RPP yang dikembangkan, yaitu silabus dan RPP PKBM-PS 4T (Pembelajaran Kuantum Berbasis Masalah dengan Pendekatan Saintifik 4 Tahap), silabus dan RPP PKBM-PS 6T (Pembelajaran Kuantum Berbasis Masalah dengan Pendekatan Saintifik 6 Tahap), silabus dan RPP PKTBM-PS 4T (Pembelajaran Kuantum Tanpa Berbasis Masalah dengan Pendekatan Saintifik 4 Tahap), dan silabus dan RPP PKTBM-PS 6T (Pembelajaran Kuantum Tanpa Berbasis Masalah dengan Pendekatan Saintifik 4 Tahap). LAS yang dikembangkan meliputi LAS PKBM dan LAS PKTBM. Hasil validasi perangkat pembelajaran dan uji kelompok kecil disajikan pada Tabel 3 dan Tabel 4. 
Tabel 3. Rekapitulasi validasi perangkat pembelajaran

\begin{tabular}{llccccc}
\hline \multirow{2}{*}{ No } & \multirow{2}{*}{ Komponen Perangkat Pembelajaran } & \multicolumn{3}{c}{ Validator } & Rata-rata & \multirow{2}{*}{ Kriteria } \\
\cline { 3 - 5 } & & A & B & C & nilai & \\
\hline 1. & Silabus PKBM-PS 4T & 30 & 38 & 33 & 33,67 & Layak \\
2. & Silabus PKBM-PS 6T & 31 & 38 & 32 & 33,67 & Layak \\
3. & Silabus PKTBM-PS 4T & 31 & 38 & 33 & 34,00 & Layak \\
4. & Silabus PKTBM-PS 6T & 31 & 38 & 33 & 34,00 & Layak \\
5. & RPP PKBM-PS 4T & 32 & 43 & 37 & 39,33 & Layak \\
6. & RPP PKBM-PS 6T & 37 & 43 & 37 & 39,00 & Layak \\
7. & RPP PKTBM-PS 4T & 31 & 43 & 37 & 37,00 & Layak \\
8. & RPP PKTBM-PS 6T & 33 & 43 & 37 & 37,00 & Layak \\
9. & LAS PKBM & 29 & 35 & 34 & 32,67 & Sangat Layak \\
10. & LAS PKTBM & 29 & 35 & 34 & 32,67 & Sangat Layak \\
11. & Tes Kemampuan Berpikir Kritis & 29 & 31 & 30 & 30,00 & Sangat Layak \\
12. & Tes Kemampuan Berargumen & 28 & 31 & 29 & 29,33 & Sangat Layak \\
\hline
\end{tabular}

Tabel 4. Rekapitulasi hasil uji kelompok kecil

\begin{tabular}{lccc}
\hline \multirow{2}{*}{ Aspek yang dinilai } & \multicolumn{2}{c}{ LAS } & \multirow{2}{*}{ Rata-rata } \\
\cline { 2 - 3 } & PKBM & PKTBM & \multirow{2}{*}{3,6} \\
1. Kejelasan kalimat petunjuk pengerjaan & 3,4 & 3,5 & 3,45 \\
2. Kejelasan kalimat soal & 3,4 & 3,5 & 3,4 \\
3. Kemenarikan tampilan dan gambar pada LAS & 3,7 & 3,1 & 3,4 \\
4. Kesesuaian LAS untuk membangkitkan & 3,4 & 3,4 & \\
motivasi/minat/rasa ingin tahu & 3,9 & 3,6 & 3,75 \\
5. Kesesuaian antara gambar dengan uraian materi & 17,8 & 17,2 & \\
\hline Nilai & Sangat & Sangat \\
\hline Kriteria kelayakan & Layak & Layak \\
\hline
\end{tabular}

Berdasarkan hasil validasi diketahui bahwa perangkat pembelajaran yang telah dikembangkan berada pada kategori layak dan sangat layak untuk diterapkan pada mata pelajaran biologi materi ekologi untuk meningkatkan kemampuan berpikir kritis dan kemampuan berargumen siswa kelas X. Hasil uji kelompok kecil menunjukkan bahwa LAS sangat layak.

Silabus dikembangkan berdasarkan Permendiknas Nomor 41 Tahun 2007 yang memuat identitas mata pelajaran atau tema pelajaran, SK, KD, materi pembelajaran, kegiatan pembelajaran, indikator pencapaian kompetensi, penilaian, alokasi waktu dan sumber belajar. Komponen RPP yang dikembangkan meliputi identitas sekolah, kompetensi inti, kompetensi dasar, indikator, tujuan pembelajaran, materi pembelajaran, model pembelajaran, metode pembelajaran, pendekatan pembelajaran, kegiatan pembelajaran yang mencakup 5 kali pertemuan, penilaian, sumber belajar, dan pengesahan RPP oleh guru mata pelajaran dan kepala sekolah.

Kegiatan pendahuluan dalam RPP direncanakan agar dapat menggugah timbulnya pertanyaan pada diri siswa. Kegiatan inti ditujukan untuk terkonstruksinya konsep, hukum 
atau prinsip oleh siswa dengan bantuan dari guru. Kegiatan penutup ditujukan untuk memperkuat konsep yang telah dibangun oleh siswa serta merayakan usaha dan kerja keras siswa agar tumbuh motivasi, rasa menghargai, dan percaya diri. Hasil penelitian yang dilakukan oleh Jayanti (2011) yang menunjukkan bahwa siswa menjadi lebih termotivasi dan aktif belajar akibat kegiatan belajarnya difasilitasi dengan memberikan pengalaman belajar melalui sajian masalah yang ditemui dalam kehidupan sehari-hari.

LAS yang dikembangkan berisi komponen masalah yang terstruktur dengan baik. Hal ini memungkinkan siswa untuk menyajikan lebih dari satu strategi penyelesaian yang cocok dan memerlukan informasi tambahan untuk menyelesaikan permasalahan. Kirkley (dalam Widjayanti, 2009) menyebutkan ada 3 jenis masalah, yaitu: (1) masalah-masalah yang terstruktur dengan baik (well structured problems), (2) masalah-masalah yang terstruktur secara cukup (moderately structured problems), dan (3) masalah-masalah yang strukturnya jelek (ill structured problems). Masalah yang terstuktur dengan baik, strategi untuk menyelesaikannya biasanya dapat diduga, mempunyai satu jawaban yang benar, dan semua informasi awal biasanya bagian dari pernyataan masalahnya. Masalah yang terstruktur secara cukup, sering mempunyai lebih dari satu strategi penyelesaian yang cocok, mempunyai satu jawaban yang benar, dan masih memerlukan informasi tambahan untuk menyelesaikannya. Masalah-masalah yang strukturnya jelek, penyelesaiannya tidak terdefinisi dengan baik dan tidak terduga, mempunyai banyak perspekif, banyak tujuan, dan banyak penyelesaian, serta masih memerlukan informasi tambahan untuk menyelesaikannya.

LAS tanpa berbasis masalah dikembangkan tanpa mengesampingkan tuntutan peningkatan kemampuan berpikir kritis dan kemampuan berargumen siswa. Agar LAS PKTBM dapat menarik perhatian siswa maka penyajian LAS dilengkapi dengan warnawarna dan gambar yang menarik.

Kolaborasi antara gambar dan warna merupakan bagian penting untuk memaksimalkan stimulus ke dalam otak. Memahami kaitan antara pandangan sekeliling dan otak adalah penting dalam rangka mengorkestrai lingkungan belajar yang mendukung (DePorter, 2003). Perangkat PKBM yang dilengkapi dengan LAS berbasis masalah menjadi media pembelajaran yang memudahkan proses pembelajaran dimana siswa akan belajar memahami dan menjalankan suatu tugas secara tertulis (Chodijah, dkk, 2012)

Tes kemampuan berpikir kritis dikembangkan dalam bentuk esai. Pengembangan tes kemampuan berpikir kritis berdasarkan kebutuhan kompetensi masa depan yang 
mengharapkan peningkatan kemampuan peserta didik yang diperlukan antara lain kemampuan berkomunikasi, berpikir kritis dan kreatif sesuai dengan apa yang diharapkan oleh kurikulum 2013.

Kemampuan berargumen diukur melalui sebuah instrumen yang dikembangkan dalam bentuk tes pilihan ganda akibat-sebab. Model tes tersebut dikembangkan berdasarkan model CTSR (Classroom Test of Scientific Reasoning) oleh Lowson (1978). Model tes yang dikembangkan memuat konsep pengetahuan pada bagian soal dengan item ganjil, sedangkan soal item genap memuat konsep pemahaman yang diasimilasi dari kemampuan menganalisis, mengevaluasi, dan menyatakannya dalam bentuk argumen yang dipercayai oleh siswa merupakan alasan dari konsep pada item soal pertama.

\section{KESIMPULAN}

Berdasarkan hasil penelitian yang telah dilakukan dapat disimpulkan bahwa perangkat pembelajaran yang dikembangkan meliputi silabus dan RPP berada kategori layak, LAS, tes kemampuan berpikir kritis dan tes kemampuan berargumen berada pada kategori sangat layak untuk diterapkan pada mata pelajaran biologi materi ekologi kelas $\mathrm{X}$ SMA. Perangkat pembelajaran yang dikembangkan meliputi silabus, RPP, LAS, tes kemampuan berpikir kritis dan tes kemampuan berargumen. Silabus memiliki karakteristik yaitu mengandung indikator pembelajaran yang memuat indikator kemampuan berpikir kritis dan kemampuan berargumen. RPP mendorong partisipasi aktif peserta didik dengan cara meningkatkan motivasi dan rasa ingin tahu. Pengalaman dan kegiatan pembelajaran yang dimuat di silabus dan RPP dikembangkan berdasarkan sintaks model PKBM-PS 4T, PKBM-PS 6T, PKTBM-PS 4T dan PKTBM-PS 6T. LAS berbasis masalah memuat konteks permasalahan yang diangkat dari kehidupan di sekitar siswa terkait materi ekologi dan dikemas dalam struktur yang cukup baik dengan tujuan untuk mencari lebih dari satu strategi penyelesaian yang cocok dan memerlukan informasi tambahan untuk menyelesaikannya. LAS PKTBM tidak memuat konsep masalah namun dilengkapi dengan warna dan gambar yang menarik terkait dengan konsep soal pada LAS. Penilaian terhadap kemampuan berpikir kritis dilakukan menggunakan tes esai dan kemampuan berargumen dinilai menggunakan tes pilihan ganda akibat-sebab. 


\section{DAFTAR PUSTAKA}

Arnyana, I.B.P. 2006. Pengaruh Penerapan Strategi Pembelajaran Inovatif pada Pelajaran Biologi terhadap Kemampuan Berpikir Kreatif Siswa SMA. Jurnal Pendidikan dan Pengajaran IKIP Negeri Singaraja, No. 3 TH. XXXIX Juli 2006.

Chodijah, S, Fauzi, A, Wulan, R. 2012. Pengembangan Perangkat Pembelajaran Fisika Menggunakan Model Guided Inquiry yang Dilengkapi Penilaian Portofolio pada Materi Gerak Melingkar. Jurnal Penelitian Pembelajaran Fisika 1(2012) 1-19. (online) $\quad$ http://ejournal.unp.ac.id/index.php/jppf/article/download/603/521. Diakses tanggal 20 Agustus 2014.

DePorter, B. Reardon, M, Nourie, S.S. 2003. Quantum Teaching. Bandung: Kaifa.

Dick,W, Carey, L, Carey, J.O. 2001. The Systematic Design of Instruction. United States: Addison-Wesley Education Publisher.

Dokumen Bahan Ajar Training of Trainer (ToT ) Implementasi Kurikulum 2013. 2013. Kementerian Pendidikan dan Kebudayaan. (online): http://180.247.119.246/materi/invest/UPLOAD\%201/Presentasi\%20baru/DRAF \%20_1Jayakarta\%20BAHAN\%20\%20AJAR\%20.doc. Diakses tanggal 27 Januari 2014.

Undang-Undang Repiblik Indonesia Nomor 14 Tahun 2005 tentang Guru dan Dosen dan Undang-Undang Nomor 20 Tahun 2003 tentang Sisdiknas (Sistem Pendidikan Nasional) Beserta Penjelasannya. 2006. Bandung: Fermana.

Erdurane, S, Simon, S, Osborne, J. 2004. TAPping into Argumentation:Developments in the Application of Toulmin's Argument Pattern for Studying Science Discourse. (online): http://eprints.ioe.ac.uk/654/1/Erdurane2004TAPing915.pdf. Diakses tanggal 20 Desember 2013.

Jayanti, M.I. 2011. Penerapan Model Pembelajaran Kuantum dan Kooperatif Tipe NHT (Numbered Head Together) pada Pelajaran Biologi serta Implikasinya terhadap Hasil Belajar Siswa di SMAN 1 Gunungsari. Skripsi. Universitas Mataram.

Lawson, A.E. 1978. Development and Validation of the Classroom Test of Formal Reasoning. Journal of Research in Science Teaching, 15(1): 11-24.

OECD. 2013. Indonesia Student performance (PISA 2012). (online) : http://www.oecd.org/pisa/aboutpisa/pisa-2012-participants.htm. Diakses tanggal 8 Januari 2014.

Prasetyo, I.F, Santosa, S. Karyanto, P. 2012. Pengaruh Penerapan Quantum Learning terhadap Hasil Belajar Biologi Siswa Kelas X SMA Negeri 4 Surakarta Tahun Pelajaran $2011 / 2012$. (online): http://jurnal.fkip.uns.ac.id/index.php/prosbio/article/download/1025/678. Diakses tanggal 12 Mei 2013. 
Sugiyono. 2011. Statistika untuk Penelitian. Bandung: Alfabeta.

Suryawati, E. 2012. Pengembangan Pembelajaran Kontekstual RANGKA Berbasis Pendidikan Karakter untuk Meningkatkan Sikap Ilmiah dan Keterampilan Berpikir Kritis Siswa SMA dalam Pembelajaran Biologi. Solo: Prosiding Seminar Nasional Sains 2012.

Widjajanti, D.B. 2009. Kemampuan Pemecahan Masalah Matematis Mahasiswa Calon Guru Matematika: Apa dan Bagaimana Mengembangkannya. Seminar Nasional FMIPA UNY 5 Desember 2009. 